are Dr. Kitasato's Results of Pure Cultures of 'Tubercle Bacilli and other Pathogenic Bacteria from Sputum, and that of Professor Dujardin-Beaumetz on the Liver as a Bile-making Organ. In the monthly bulletin from the Laboratory of Hygiene, by Drs. Kellogg and Paquin, we find an account of some Experiments on the Relative Influence of Gorms and their Prodncts in the Production of Disease, and a continued (illustrated) article on Liver Flukes in Cattle.

Fener Nursing: a Course of Lectures on the Nursing Required in Cases of Ordinary Fever. By MARY HARRis, Matron of the Suffolk General Hospital, Bury St. Edmunds, Member of the Council of the Royal Britisl Nurses' Association \&c. London: The Record Press, Limited, 376, Strand, W.C. 1892.-This is a good sample of the Record "Booklet" series. The authoress tells us that the articles originally appeared in 1888 in the Nursing Record in a serial form, and that they are republished in consequence of the numbers of the journal in which they appeared being out of print. The nursing and management of the following diseases are dealt with-riz., scarlet fever, typhoid fever, typhus fever, chicken-pox and small-pox; and at the end a couple of pages of examination questions are added. We have been much gratified with our perusal of this little book, which, if it makes no claim to originality, nevertheless contains much sound and useful information well put together. The salient pathological and medical points connected with these fevers, with which every intelligent and educated nurse should be acquainted, are clearly and sufficiently set forth, as well as those points which have a direct practical bearing on the nursing and management of these diseases.

Aix-ln-Chapelle as a Health Resort. By Drs. Alexander, Beissel, Brandis, Goldstein, Mayer, Rademaker, SCHUMACHER and THISSEN. The English edition, translated with the sanction of the civic authorities by JAMES DONELAN, M.B., M.Ch., B.A.O. \&c. London: J. \& A. Churchill. 1892. - This work consists of a general description of Aix-laChapelle and its baths, together with a collection of essays by the physicians of the locality. "The baths," we are told, "vary in temperature from $47^{\circ}$ to $74 \cdot 6^{\circ} \mathrm{C}$. ...... The douche is always administered in the bath itself. The doucheur or doucheuse enters the bathroom with the patient, and supplements the action of the douche by means of kneading and massage, or moderates the force of the jet with his hand, while he allows it to play in a slanting direction. The patient does not need to go into a separate douche-room, as is the custom in so many other establishments, but he remains some time longer in the bath after the douche in order to assist its action. Vapour baths have been placed in all the bath houses, and are supplied by the natural hot vapours of the thermal waters, which are formed either at the outlet of the lower spring or whilst flowing down in one of the channels fed by the principal spring. ...... The vaporised thermal water can also be inhaled by suitable spray apparatus." The second part of the work contains papers on the Treatment of Gout, Chronic Rheumatic Arthritis, Arthritis Deformans, Diseases of the Skin, Injuries and their Consequences, Chronic Catarrh of the Digestive Iract, Chronic Catarrh of the Pharynx, Larynx and Bronchi, Syphilis, Diseases of the Nervous System, Tabes Dorsales, Syphilitic Diseases of Internai Organs, Chronic Metallic Poisoning and Diseases of the Eyes. The translation appears to have been done carefully, though here and there little Germanisms may be letected; and in the list of chemical constituents of the waters we find "iodide of soda," "chloride of ammoni $a$," and "phosphate of sod $a$." 'These are, however, but mere verbal defects in a very valuable scientific account of one of the most important thermal springs in Europe, which will well repay perusal by any physician who thinks of sending a patient to Aix-la-Chapelle.
IIandhuch der Thysiologische Optill. Von H. voN HeLMnoLn\%. 2te Aufgabe, 7te Lieferung. Hamburg and Leipsic: Voss. 1892. - The issue of the parts of this important work proceeds with unaccountable slowness. No doubt Helmholtz is a very busy man, and it cannot be denied that considerable additions have been macle to the original treatise; but the first part of the second edition appeared in Norember, 1885. It. was announced that the work would be completed in ten parts ; the seventh part is now reached, and only about half the work is finished, whilst seven years have elapsed. If the same time is taken for the second half, a revision of the first 500 pages will be requisite. The present part deals with the phenomena produced by quickly recurring impressions, such as those obtained by spinning tops with coloured discs and the images obtained by Maybridge and Auschütz, which, the author rightly observes, present the movements of animals with extraordinary fidelity and supply important information in regard to the muscular movement of animals. The part also contains an account of after-images and of contrast and complimentary colours, ancl concludes with some observations upon induced colours.

The Journal of Physiology. Edited by MICHAEL Foster. Vol. XIII., No. 6. Cambridge Engraving Company. October, 1892. - This part contains the following memoirs: T. D. Harris and W. J. Gow, Ferment Actions of the Pancreas in Different Animals ; R. T. Hewlett, Fractional Heat Coagulation; W. 'T. Porter, Researches on the Filling of the Heart, with two plates ; J. N. Langley and H. K. Anderson, on the Mechanism of the Movements of the Iris; A. E. Garrod, on the Occurrence and Detection of Hæmatoporphyrin in the Urine, with a plate; C. S. Sherrington, Notes on the Arrangement of some Motor Fibres in the Lumbosacral Plexus, with four plates.

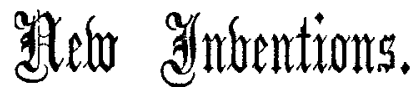

\section{SACKLINS' PATENT READY-MADE POULTICES.}

THE linseed poultices are made with the best crushed linseed, containing the full quantity of oil, and the linseed is sewn securely between muslin and waterproof calico, the latter keeping in the heat and moisture. They also contain 2 per cent. of boric acid, which is dissolved at the time of using and renders them antiseptic. The septic qualities of the ordinary poultice are done away with, and these poultices can be applied to an unbroken surface with safety. The sewing is done in such a manner that the linseed is secured in many square-shaped compartments, and by cutting along the seams it is possible to make them of the required size. When wanted for use, it is only necessary to pour boiling water over the poultices and to apply them. It is said that they may be redipped in boiling water and applied thirty times consecutirely without appreciable diminution of their remedial value. The least experienced nurse can hardly spoil them, and they are certainly of much greater cleanliness in use than the average poultice of domestic life; no pieces of linseed adhere to the skin on their removal, and as they are ready-made and can be at once applied, they should find a ready sale ; they are, moreover, cheap. The mustard poultices are made of pure mustard flour and ground mustard husk which contains a large percentage of bland oil, and prevents the painful effect of the mustard They are mild and are said not to blister the skin should the patient fall asleep and wear one all night; they can therefore be tolerated for a long time and the effect of the counter-irritant is made more lasting. They are manufactured by Messrs. Sacklins and Co., 20, Royal Exchange. 


\section{INSTRUMEN'TS FOR BONE SUTURE.}

ANNEXED is a woodcut of the bradawl and director used at the West London Hospital in suturing bones, either by subcutaneous or by open operation. They were made for me by Messrs. Maw, Son and Thompson in April, 1889. The bradawl is of one piece of steel, without any angles or mouldings to collect dirt, and is nickel-plated. These peculiarities are, of course, for ease of purification. It is also used for aseptic cases only. The director is a size less in diameter than the bradawl and ought to be of uniform calibre throughout. That it is not quite so in the specimen drawn is an accidental error. Like the bradawl it is of steel, nickel-plated. The blade of the bradawl is $3 \frac{1}{4} \mathrm{in}$. long and of a size intermediate between a No. 8 and No. 9 catheter (French scale). The director is of the size of a No. 7 (French) and the wire generally employed is equal in thickness to No. 3 (French). The length of the bradawl is a great convenience and is intended to make it available for the subcutaneous suture of superficial bones, like the patella and olecranon. About two years after these instruments had been constructed first a long drill-bit perforated at the end, and afterwards a long bradawl, also perforated at the end, were described and recommended for subcutaneous suture. The idea of a perforated bradawl was rejected at the time when the instruments I am describing were first planned, as tending to at once increase thickness and diminish strength ;
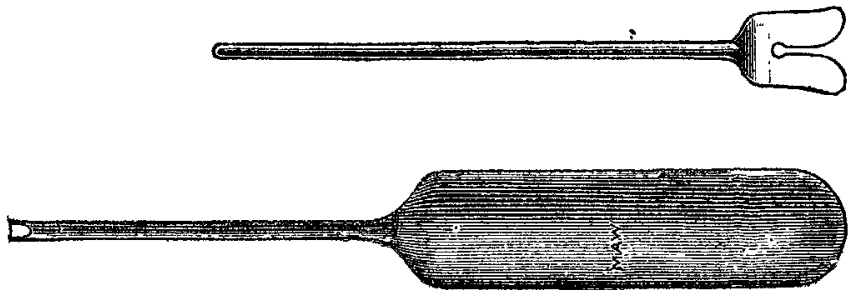

for a too thick awl will split a patella and a thin and perforated awl is liable to break. These are not mere theoretical objections: I have seen the patella split in three cases and I have in my possession the broken stump of a perforated bradawl made two years and a half ago. With the longbladed awl and director to match I have sutured various bones, including the femur, the tibia, the patella, the olecranon and the astragalus and scaphoid. The director should be passed as far as the bone along the awl before the latter is withdrawn; and of course the wire, previously straightened, is slipped through in the groove of the director. When wiring subcutaneously the wire, after passing through the bone fragments and emerging at the second skin aperture, is returned through the same aperture along the director, previously thrust back between the skin and the bone, to the original skin opening. Also, when the awl has perforated one fragment it should be used carefully as a probe (in conjunction with digital palpation from without) to ascertain the bearings \&c. of the other fragment. In this way can be aroided the error of attaching the anterior surface of one fragment to the fractured surface of the other in a patella case. The results which can be got by such operations as Mayo Robson's show that the inversion of periosteum between fragments of patella has not the practical importance once attached to it. Close union of any kind, either bony or fibrous, suffices in the case of a bone which is merely inserted in an aponeurosis and which does not form part of the main skeleton. The openings made for and by the awl and director give ready egress to all liquid effusions, but not of course to clots.

Grosvenor-street, $\mathrm{W}$.

C. B. KeEtley, F.R.C.S. Eng.

\section{THE HECLA FOOT AND BED WARMER}

Messra. W. Shirley and Co. of Lord-street, Wolverhampton, have submitted to our inspection a specimen of the above appliance. It consists of a cylindrical vessel about a foot in length, made of block tin, with a screw stopper, and enclosed in a woollen jacket. The convenience of form renders it applicable to the two purposes of bed-airing and footwarming. It is cheap and handy, and is likely to prove a welcome adjunct to household comfort.
THE COMMON ROOM FOR FELLOWS AND MEMBERS OF THE ROYAL COLLEGE OF SURGEONS OF ENGLAND.

In pursuance of a resolution of the Council of the Royal College of Surgeons of England the room, adjoining the secretary's office, which formed part of the library not used by readers has been furnished as a common room for the use of Fellows and Members of the College. The room, which is spacious, and looks on to the garden of Lincoln's-inn-fields, has been handsomely and comfortably furnished with a Turkey carpet, two walnut octagonal tables, writing tables, settee, and a suite covered in morocco leather, together with a hat stand and umbrella stand. The principal daily and weekly newspapers are also provided. The regulations for the common room are the following:-

1. The common room is open to Fellows and Members of the College only. 2. The common room is open on each weekday from 11 A.M. till 5 P.M. except Saturdays, when it is open from 11 A.M. to 1 P.M. It is closed during September and at such other times as the Council may direct. 3. No formal meeting of any description may be held in the common room. 4. Fellows and Members writing letters at the College may not use the College as their address.

"Note. - Fellows and Members are reminded that smoking is not permitted in any part of the College premises.

"Nov. 10th, 1892." "EDWARD TRIMMER, Secretary.

The common room was opened on the day of the Bradshaw Lecture, Thursday, December 1st. A good fire is kept burning and the room wears a cheerful and comfortable aspect. Writing materials are provided. Probably very few of the Fellows and Members of the College are at present aware that a common room is in existence and it may be anticipated that it will be found useful by those who frequent the library and museum, or attend the lectures and meetings at the College. The room was obtained for the Fellows and Members through the application of the Association of Fellows to the Council of the College.

\section{THE DENTAL HOSPITAL OF LONDON.}

THE annual dinner of the past and present students of this institution was held on Saturday last at the Café Royal. Sir Richard Quain, F.R.S., supported by Dr. Hare and Mr. Bryant, the President of the Royal College of Surgeons, occupied the chair. The health of the past and present students having been proposed and duly honoured, the chairman alluded to some of the more distinguished men who had passed through the hospital and school. Referring to the action of the General Medical Council, he said they are willing to take, and are taking, great interest in advancing this department of the healing art, and he could assure his hearers that that body would do all in their power to help the dentists; but they must help themselves, and he could prophesy a great future for them if they would avoid unprofessional actions and devote themselves earnestly to their noble profession. Mr. Bryant recognised in the hospital a valuable institution for the treatment of the suffering poor, and in the school an excellent educational establishment which provided properly qualified and skilled dental surgeons for the rich. Dr. Hare, replying for the hospital, urged its claims upon public sympathy and monetary support to provide increased space and larger opportunities for work. Dealing mainly with statistics, the dean of the school, Mr. Morton Smale, said that the development which had taken place on the scientific side of dental surgery, and the fact that it was now a legalised profession, had produced two results--first, an immense increase in the number of cases treated (last year the numbers were 54,177); and, secondly, a large increase in the number of students. This tended to a crowded state of an already over-burdened institution, and the only remedy was to provide a new and more commodious hospital building. Such a change would necessitate an expenditure of $£ 40,000$, of which $£ 3000$ had already been promised by members of the staff and friends. He was confident that the public would soon provide the remainder. An excellent programme of music, which was partly contributed by the Hospital Glee Society, added to the enjoyment of the evening. 